\title{
Kepuasan Nasabah dan Strategi Pengembangan Usaha BNI Kantor Cabang Utama Harmoni Jakarta
}

\author{
Enrico Annas \\ Program Studi Magister Profesional Industri, Sekolah Pascasarjana \\ Institut Pertanian Bogor \\ Kampus Baranangsiang Bogor 16680 \\ Musa Hubeis \\ Departemen Manajemen, Fakultas Ekonomi dan Manajemen \\ Institut Pertanian Bogor \\ Kampus Dramaga Bogor 16680 \\ e-mail: hubeis.musa@yahoo.com \\ Sapta Raharja \\ Departemen Teknologi Pertanian, Fakultas Teknologi Pertanian \\ Institut Pertanian Bogor \\ Kampus Dramaga Bogor 16680
}

\begin{abstract}
Banking industry has been growing rapidly fast in Indonesia, shown by many newly established banks and their various products, leading to significantly tough competition. Moreover, there have been changes in consumer mindset characterized by the increase number of factors to be considered in choosing a bank, including easy access, security, competitive products and satisfying services. The purposes of the study were to identify the characteristics of customers, to analyze the correlation between the performance quality of the services and the characteristics of the customers, to analyze the level of interest of the clients with the quality of services attributes according to customers' performance and to develop strategies appropriate for the development of Bank Negara Indonesia (BNI) Branch Offices Harmoni in facing competitions. The methods used in this research are descriptive analysis, reliability and validity test, chi-square, cross tabulation, Importance Performance Analysis (IPA), Customer Satisfaction Index (CSI) and Strengths, Weakness, Opportunities and Threats (SWOT) analysis. Customer characteristics of BNI KCU Harmoni majority were woman, aged 36-55 years, worked as employees whose monthly income was above 8 million rupiah. In general, customers gained information from the banner placed in front of the BNI KCU Harmoni office. Based on the relationship between customers' characteristics and the level of performance, it can be concluded that female customers, especially those who were 36-55 years required services that meet their needs. Employees required services in accordance with service standards. Customers with income Rp.5-8 million expected financial transactions to take place safely. Customer carried out transactions once a month because they felt confident and comfortable with the services provided. Moreover, the banner placed in front of BNI KCU Harmoni was found to very helpful in providing information. The main improvement proposed to be conducted include providing better parking services that can be coordinated with building operational security and conducting more aggressive, and informative marketing, and focused on surrounding office. Overall, the results of the integration of science, CSI and SWOT showed that customers were satisfied with the service provided BNI KCU Harmoni. The satisfaction should be compared (benchmarking) with the services provided by the bank competitors around BNI KCU Harmoni so that the service can be improved for the better.

Keywords : customer service, banking competition, information and strategic
\end{abstract}




\section{ABSTRAK}

Industri perbankan di Indonesia berkembang dengan cepat, ditunjukkan dengan banyaknya bank dan produknya yang menyebabkan persaingan semakin ketat. Disamping itu, terjadinya perubahan pola pikir konsumen yang ditandai dengan semakin banyaknya faktor yang menjadi pertimbangan dalam memilih bank, antara lain akses yang mudah, rasa aman, produk bersaing dan pelayanan memuaskan. Tujuan kajian untuk mengidentifikasi karakteristik nasabah, menganalisis hubungan tingkat kinerja mutu jasa yang diberikan dengan karakteristik nasabah, menganalisis tingkat kepentingan nasabah dengan atribut-atribut mutu pelayanan, menganalisis kesesuaian antara tingkat kepentingan dengan atributatribut mutu pelayanan menurut nasabah dengan kinerja dan menyusun strategi yang tepat untuk pengembangan Bank Negara Indonesia (BNI) Kantor Cabang Utama (KCU) Harmoni dalam menghadapi persaingan. Metode yang digunakan dalam kajian ini adalah analisis deskriptif, keandalan dan uji validitas, khi-kuadrat (chi-square), tabulasi silang, Importance Performance Analysis (IPA), Customer Satisfaction Index (CSI) dan Strengths, Weaknesses, Opportunities and Threats (SWOT) analysis. Karakteristik nasabah BNI KCU Harmoni sebagian besar adalah wanita berusia 36-55 tahun dan bekerja sebagai karyawati dengan penghasilan di atas Rp 8 juta lebih. Secara umum, nasabah mendapatkan informasi dari spanduk yang dipasang di depan kantor BNI KCU Harmoni. Berdasarkan hubungan antara karakteristik nasabah dan tingkat kinerja, dapat disimpulkan bahwa pelanggan wanita, terutama berusia 36-55 tahun membutuhkan pelayanan sesuai dengan yang dibutuhkan. Karyawan membutuhkan pelayanan menurut standar layanan. Nasabah dengan penghasilan Rp 5-8 juta mengharapkan transaksi keuangan dilakukan dengan aman. Nasabah melakukan transaksi sekali dalam satu bulan, karena merasa percaya dan nyaman dengan pelayanan yang diberikan. Sumber informasi berupa spanduk yang dipasang di depan BNI KCU Harmoni sangat membantu petugas dalam memberikan informasi. Prioritas utama perbaikan perlu dilakukan tentang pelayanan parkir dengan melakukan koordinasi keamanan operasional gedung dan melakukan pemasaran secara agresif, lebih informatif dan fokus dengan lingkungan di sekitar kantor. Secara keseluruhan dari hasil integrasi IPA, CSI dan SWOT menunjukkan bahwa nasabah telah merasa puas dengan pelayanan yang telah diberikan BNI KCU Harmoni. Kepuasan ini harus dibandingkan (benchmarking) dengan pelayanan yang diberikan oleh bank-bank pesaing di sekitar BNI KCU Harmoni agar pelayanan dapat lebih ditingkatkan menjadi lebih baik.

Keywords : customer satisfaction, pengembangan bisnis, strategi

\section{Pendahuluan}

Perkembangan bisnis perbankan di Indonesia begitu pesat, ditandai dengan jumlah bank yang semakin banyak dan produk semakin variatif. Disamping itu, terjadinya perubahan pola pikir konsumen yang ditandai dengan semakin banyaknya faktor yang menjadi pertimbangan dalam memilih bank, antara lain akses yang mudah, rasa aman, produk bersaing dan pelayanan memuaskan. Bisnis perbankan adalah bisnis jasa, salah satu cirinya adalah setiap transaksi yang terjadi memerlukan kontak langsung antara petugas bank dengan konsumen.

Pertambahan jumlah bank menimbulkan meningkatnya persaingan antara industri perbankan. Persaingan bukan saja antara lembaga industri perbankan itu sendiri, akan tetapi juga persaingan antara industri perbankan dengan lembaga keuangan bukan bank dan pasar modal. Kompetisi bisnis di masa mendatang akan diwarnai dengan perubahan kompleks dari berbagai kombinasi faktor-faktor seperti politik, ekonomi, teknologi, sosial dan budaya, disamping pengaruh dari faktor pelaku bisnis bersangkutan, sehingga persaingan bisnis antar perusahaan relatif ketat, baik di pasar domestik maupun internasional. Keadaan ini apabila tidak disadari maupun diantisipasi, membuat para pelaku bisnis sulit memposisikan dirinya secara baik dan benar dibandingkan dengan pesaingnya dalam merebut konsumen (Hubeis 1997). Perusahaan yang ingin mendapat keunggulan kompetitif perlu menghasilkan produk 
(barang atau jasa) yang bermutu dengan harga bersaing, waktu penyerahan yang lebih cepat dan pelayanan yang baik kepada nasabah (Subihaini 2002).

Dalam era globalisasi yang sedang dihadapi Indonesia telah menyebabkan setiap perbankan harus siap menghadapi persaingan sangat ketat untuk mendapatkan pangsa pasar yang besar. Hal ini berarti produk, baik barang atau jasa yang dihasilkan harus sesuai dengan harapan dan kebutuhan nasabah. Nasabah adalah kunci bagi kesuksesan perbankan. Peran yang demikian penting telah membuat perusahaan berupaya untuk menariknya, sehingga menjadi pembeli produknya. Untuk sampai kepada tujuan itu, bank kemudian menyusun strategi bagi nasabah secara spesial. Dalam hal ini, mutu pelayanan sangat ditentukan oleh kemampuan bank dalam memahami kebutuhan dan persepsi nasabah. Artinya kemampuan dan kepekaan bank dalam menangkap apa yang menjadi harapan nasabah adalah sangat menentukan baik dan buruknya pelayanan yang diberikan. Oleh karena itu, untuk mengetahui tingkat kepuasan nasabah perbankan terhadap mutu pelayanan, perlu dilakukan kajian yang membandingkan tingkat kepentingan nasabah terhadap atribut di Bank Negara Indonesia (BNI) Kantor Cabang Utama (KCU) Harmoni menurut tingkat kinerja, yang pada akhirnya dapat mengetahui tingkat kepuasan nasabah. Persaingan yang semakin ketat telah mengakibatkan perusahaan harus menetapkan strategi yang tepat untuk memenangkan persaingan dan antisipasi guna untuk memenangkan persaingan, atau mampu bertahan menghadapinya.

BNI KCU Harmoni sebagai salah satu KCU BNI yang terdepan dilingkungan BNI Pusat, karena terletak di daerah pusat bisnis Jakarta harus melakukan berbagai jenis upaya dalam kegiatan pemasarannya, agar menarik dan sesuai dengan keinginan dan harapan nasabah. Pelaksanaan pelayanan terhadap nasabah merupakan salah satu jenis kegiatan dalam program pemasaran yang menjadi salah satu perhatian nasabah dalam memilih suatu produk perbankan. Pelaksanaan pelayanan terhadap nasabah sangat dipengaruhi oleh mutu dari pelayanan itu sendiri. Jumlah nasabah BNI pada saat ini (per Maret 2013) telah mencapai 14,5 juta rekening. Tujuan kajian ini adalah 1) Mengidentifikasi karakteristik nasabah BNI KCU Harmoni; 2) Menganalisis hubungan tingkat kinerja mutu jasa yang diberikan dengan karakteristik nasabah; 3) Menganalisis tingkat kepentingan nasabah dengan atribut-atribut mutu pelayanan BNI KCU Harmoni; 4) Menganalisis kesesuaian antara tingkat kepentingan dengan atributatribut mutu pelayanan menurut nasabah dengan kinerja BNI KCU Harmoni, dan 5) Menyusun strategi yang tepat untuk pengembangan BNI KCU Harmoni dalam menghadapi persaingan.

\section{Metode Penelitian}

Kajian dilakukan di BNI KCU Harmoni yang berlokasi di Jl. Gajahmada, Jakarta. Penelitian ini dilaksanakan selama bulan Juni-Agustus 2013. Kajian ini menggunakan data primer dan sekunder yang bersifat kualitatif maupun kuantatif. Data primer adalah data yang diperoleh langsung dari nasabah berupa jawaban terhadap pertanyaan dalam kuesioner. Data sekunder adalah data yang diperoleh melalui data yang telah diteliti dan dikumpulkan oleh pihak lain yang berkaitan dengan permasalahan yang dikaji (Arikunto 2006). 
Sumber data adalah nasabah BNI KCU Harmoni yang dimintai tanggapan melalui kuesioner tanpa membedakan status, dengan tujuan informasi yang dihasilkan benarbenar mewakili seluruh keinginan nasabah BNI KCU Harmoni. Pemilihan dan penentuan responden dilakukan dengan accidental (non probability) sampling, yaitu responden dipilih berdasarkan kesediaannya untuk mengisi kuesioner, dengan jumlah contoh 100 responden. Jumlah ini dianggap cukup untuk mewakili, karena lebih besar dari syarat minimum 30 responden (Freund and Williams 1974).

Pengumpulan data menggunakan kuesioner tertutup berisikan sejumlah pertanyaan tertulis yang dijawab oleh responden, sehingga diperoleh data lapangan/ empiris untuk memecahkan masalah penelitian dan menguji hipotesis yang telah ditetapkan (Supardi 2005). Kuesioner dalam kajian ini didasarkan pada lima (5) dimensi mutu pelayanan atas 20 atribut yang dimuat pada Tabel 1. Atribut tersebut dikembangkan melalui studi literatur dan diskusi yang melibatkan pihak BNI KCU Harmoni.

Tabel 1. Atribut mutu pelayanan BNI KCU Harmoni

\begin{tabular}{|c|c|}
\hline No. & ATRIBUT MUTU PELAYANAN \\
\hline & RELIABILITY (Keandalan) \\
\hline 1 & $\begin{array}{l}\text { Menu pelayanan (pembukaan rekening, setoran, transfer, penarikan, dan lain-lain) } \\
\text { yang ditawarkan lengkap. }\end{array}$ \\
\hline \multirow[t]{2}{*}{2} & Pelayanan dilakukan dengan cepat dan tepat. \\
\hline & RESPONSIVENESS (Daya tanggap) \\
\hline 3 & Petugas cepat tanggap dalam memberikan pelayanan. \\
\hline 4 & $\begin{array}{l}\text { Karyawan yang menerima pertanyaan, serta keluhan dapat langsung menjawab } \\
\text { dan mampu menyelesaikan keluhan/masalah. }\end{array}$ \\
\hline \multirow[t]{2}{*}{5} & Petugas memberikan informasi yang jelas dan mudah dimengerti \\
\hline & ASSURANCE (Kepastian) \\
\hline 6 & $\begin{array}{l}\text { Pengetahuan dan keterampilan petugas dalam memberikan pelayanan kepada } \\
\text { nasabah. }\end{array}$ \\
\hline 7 & Petugas keamanan (satpam) melayani dengan ramah dan sopan. \\
\hline 8 & $\begin{array}{l}\text { Petugas pelayanan memberikan pelayanan dan informasi dengan sikap ramah dan } \\
\text { sopan. }\end{array}$ \\
\hline 9 & Kejujuran karyawan dalam berkerja \\
\hline 10 & $\begin{array}{l}\text { Keamanan selama dalam pelayanan dan kepercayaan terhadap pelayanan yang } \\
\text { diberikan. }\end{array}$ \\
\hline \multirow[t]{2}{*}{11} & Keamanan sarana parkir kendaraan. \\
\hline & EMPATHY (Kepedulian) \\
\hline 12 & $\begin{array}{l}\text { Informasi mengenai produk yang ditawarkan lengkap dan jelas (brosur iklan, } \\
\text { pamflet, dan lain-lain) }\end{array}$ \\
\hline 13 & $\begin{array}{l}\text { Petugas berusaha mengenal dan memberikan perhatian secara individu kepada } \\
\text { nasabah yang sering melakukan transaksi. }\end{array}$ \\
\hline 14 & $\begin{array}{l}\text { Penyediaan bahan bacaan (majalah, koran, dan lain-lain) dan permen selama } \\
\text { pelayanan, atau menunggu giliran. } \\
\text { TANGIBLES (Fasilitas fisik) }\end{array}$ \\
\hline 15 & Penataan interior dan layout ruangan yang baik. \\
\hline 16 & Kebersihan, kerapian dan kenyamanan ruang pelayanan. \\
\hline 17 & Kelengkapan, kesiapan dan kebersihan alat-alat yang dipakai. \\
\hline 18 & Kerapian dan kebersihan penampilan petugas. \\
\hline 19 & Kemudahan mencapai lokasi. \\
\hline 20 & Ketersediaan fasilitas parkir memadai. \\
\hline
\end{tabular}


Analisis data dilakukan dengan analisis deskriptif dan tabulasi silang (cross-tabs). Analisis deskriptif dilakukan untuk mendeskripsikan karakteristik responden yang menggunakan jasa BNI KCU Harmoni, dengan cara menggambarkan serinci mungkin dari data yang diperoleh. Semua hasil yang diperoleh dari jawaban-jawaban responden dibuat tabulasi dan dikelompokkan atas jawaban yang sama dan kemudian dipresentasikan. Persentasi yang terbesar merupakan faktor dominan dari masingmasing peubah yang diteliti.

Ada tidaknya hubungan antara karakteristik responden, meliputi jenis kelamin, usia, pekerjaan, penghasilan per bulan, frekuensi kunjungan dan informasi keberadaan bank dengan kinerja atribut mutu jasa BNI KCU Harmoni, digunakan rumus khi kuadrat (chi-square) dan uji Tabulasi Silang. Untuk menganalisis tingkat kepentingan dan tingkat kinerja atribut mutu pelayanan BNI KCU Harmoni digunakan analisis Importance Performance Analysis (IPA) dan Customer Satisfaction Index (CSI), serta untuk perencanaan Strategi Pengembangan Bank menggunakan Strengths, Weaknesses, Oppor-tunities and Threats (SWOT) analysis.

Khi-kuadrat digunakan untuk menguji perbedaan nyata antara banyak data yang diamati dan obyek, atau jawaban yang masuk dalam masing-masing kategori dengan banyak yang diharapkan berdasarkan hipotesis nol (Sugiyono 2002). Rumus Khikuadrat adalah :

$$
\mathrm{KK}=\sum \frac{\left.\oint_{\mathrm{ij}}-E_{i j}\right)}{E_{i j}}
$$

Keterangan:

$\mathrm{O}_{\mathrm{ij}}=$ Observasi $_{\mathrm{ij}}$

$E_{i j}=$ Selisih peringkat $X_{i}$ dan $Y_{i}$

$\mathrm{KK}=$ Khi-kuadrat

$$
E_{i j}=(P r+P c) \times n
$$

Keterangan:

$\mathrm{Pr}=$ Proporsi baris

$\mathrm{Pc}=$ Proporsi kolom

$\mathrm{n}=$ Jumlah responden

Hipotesis yang digunakan adalah :

$\mathrm{H}_{0}=$ Karakteristik responden tidak berhubungan dengan kinerja atribut mutu jasa

$\mathrm{H}_{1}=$ Karakteristik responden berhubungan dengan kinerja atribut mutu jasa.

Dasar pengambilan keputusan dilakukan dengan dua (2) hal berikut :

1. Membandingkan Khi-kuadrat hitung dengan Khi-kuadrat tabel

a. Khi-kuadrat hitung < Khi-kuadrat tabel, maka Ho diterima.

b. Jika Khi-kuadrat hitung $>$ Khi-kuadrat tabel, maka Ho ditolak.

2. Berdasarkan peluang

a. Jika peluang $>0.05$, maka Ho tidak ditolak

b. Jika peluang $\leq 0.05$, maka Ho ditolak. 
Untuk mengetahui tingkat kesesuaian dilihat dari tingkat kepuasan nasabah dan harapan nasabah terhadap mutu pelayanan (kinerja) bank digunakan analisis tingkat kepentingan dan kinerja, atau IPA (Supranto 2001) berikut :

$$
\mathrm{Tki}=\frac{X_{i}}{Y_{i}} \times 100 \%
$$

Keterangan :

$\mathrm{Tk}_{\mathrm{i}}=$ Tingkat kesesuaian nasabah

$\mathrm{X}_{\mathrm{i}} \quad=$ Skor penilaian kinerja BNI KCU Harmoni

$\mathrm{Y}_{\mathrm{i}}=$ Skor penilaian harapan nasabah

Metode pengukuran CSI meliputi tahap-tahap berikut :

1. Menghitung Weighting Factor (WF), yaitu mengubah nilai rataan kepentingan menjadi angka persentase dari total rataan tingkat kepentingan seluruh atribut yang diuji, sehingga didapatkan total WF $100 \%$.

2. Menghitung Weighting Score (WS), yaitu nilai perkalian antar nilai rataan tingkat kinerja (kepuasan) masing-masing atribut dengan WF masing-masing atribut.

3. Menghitung Weighting Total (WT), yaitu menjumlahkan WS dari semua atribut mutu jasa.

4. Menghitung Satisfaction Index, yaitu WT dibagi skala maksimal yang digunakan (skala maksimal adalah 5), kemudian dikali $100 \%$.

Untuk perencanaan strategi pengembangan digunakan analisis Strenghts, Weaknesses, Opportunities and Threats (SWOT) yang mempertimbangkan faktor lingkungan internal (strenghts dan weaknesses) dan lingkungan eksternal (opportunities dan threats) yang dihadapi dunia bisnis. Analisis ini didahului dengan identifikasi posisi perusahaan melalui nilai faktor internal dan eksternal (Marimin 2005). Faktor internal (kekuatan dan kelemahan) dan eksternal (peluang dan ancaman) dianalisa dengan matriks Internal Factor Analysis Summary (IFAS) dan matriks External Factor Analysis Summary (EFAS) (Rangkuti 2006). Selanjutnya dilakukan pemetaan dengan matriks Internal External (IE) untuk mengetahui posisi perusahaan saat ini dan menghasilkan strategi pemasaran sesuai dengan situasi dan kondisi yang dihadapi, maupun yang akan diantisipasi.

\section{Hasil dan Pembahasan}

III.1. Uji Validitas dan Uji Reliabilitas

Pengujian terhadap kuesioner dilakukan melalui uji validitas dan reliabilitas yang dilakukan terhadap 100 responden yang menjadi nasabah BNI. Hasil pengujian validitas untuk masing-masing hasil pengukuran tingkat kepentingan dan tingkat kepuasan terhadap seluruh pernyataan lebih besar dari $r$ tabel pada selang kepercayaan $95 \%$, yaitu 0,1966 sehingga dapat dinyatakan valid.

Uji reliabilitas dilakukan dengan teknik $\alpha$ Cronbach dengan nilai $\alpha$ Cronbach untuk tingkat kepentingan atribut mutu jasa, yaitu $\alpha=0.600$ dan nilai $\alpha$ Cronbach untuk tingkat kepuasan $\alpha=0.601$. Berdasarkan hasil uji reliabilitas, diperoleh nilai $\alpha$ Cronbach yang lebih besar dari 0.6, maka kuesioner dapat diandalkan dan mampu 
memberikan hasil pengukuran konsisten apabila disebarkan kuesioner secara berulang kali dalam waktu yang berlainan.

\section{III.2. Karakteristik Konsumen}

Karakteristik contoh Nasabah BNI KCU Harmoni adalah sebagian besar wanita berusia 36-55 tahun, bekerja sebagai karyawati dengan penghasilan di atas Rp 8 juta per bulan dan merupakan konsumen baru yang mendapatkan informasi dari spanduk yang dipasang di depan BNI KCU Harmoni.

\section{III.3. Segmen Pasar}

Nasabah utama BNI KCU Harmoni dalam kajian ini (contoh) adalah wanita (66\%) yang sebagian besar bekerja lain-lain (20\%) dan sebagian lagi karyawati (18\%), dengan usia 36-55 tahun (32\%) dan berpenghasilan > Rp 8 juta per bulan (20\%).

III.4. Hubungan Karakteristik Nasabah dengan Tingkat Kinerja Atribut-atribut Mutu Jasa BNI KCU Harmoni

Hubungan karakteristik nasabah dengan tingkat kinerja mutu pelayanan jasa BNI KCU Harmoni dianalisis dengan tabulasi silang dan Khi-kuadrat. Nasabah yang diuji meliputi jenis kelamin, usia, tempat tinggal, pendidikan terakhir, pekerjaan, penghasilan, dan informasi keberadaan BNI KCU Harmoni yang dikorelasikan dengan 20 atribut mutu kinerja dan pelayanan jasa BNI KCU Harmoni.

\section{III.5. Hubungan Jenis Kelamin dengan Kinerja Mutu Pelayanan BNI KCU Harmoni}

Hasil analisis karakteristik nasabah menurut jenis kelamin memiliki hubungan kuat dengan penilaian kinerja atribut kelengkapan, kesiapan dan kebersihan alat-alat yang dipakai (atribut 17) dan kesediaan fasilitas parkir yang memadai (atribut 20). Dengan tingkat nyata kepercayaan 95\% diperoleh nilai peluang lebih kecil dari 0.05 dan nilai Khi-kuadrat hitung > nilai Khi-kuadrat tabel, yang berarti terdapat hubungan kuat antara jenis kelamin terhadap penilaian kinerja atribut tersebut, maka Ho ditolak dan $\mathrm{H}_{1}$ diterima. $\mathrm{Hal}$ ini menunjukkan adanya perbedaan gender dalam menghasilkan suatu output kerja yang telah ditetapkan bagi petugas BNI KCU Harmoni dalam melayani nasabah, khususnya responden berjenis kelamin wanita. Hasil uji Khi-kuadrat kinerja atribut yang berhubungan dengan jenis kelamin dapat dilihat pada Tabel 2.

Tabel 2. Uji Khi-kuadrat kinerja atribut yang berhubungan dengan jenis kelamin (gender)

\begin{tabular}{lcc}
\hline \multirow{2}{*}{ Khi-Kuadrat } & \multicolumn{2}{c}{ ATRIBUT } \\
\cline { 2 - 3 } & $\mathbf{1 7}$ & $\mathbf{2 0}$ \\
\hline Khi-kuadrat Hitung & $10.386^{\mathrm{a}}$ & $10.579^{\mathrm{a}}$ \\
Khi-kuadrat Tabel & 9.488 & 9.488 \\
Peluang & 0.034 & 0.032 \\
Keputusan & Tolak Ho & Tolak Ho \\
\hline
\end{tabular}

Berdasarkan hasil uji tabulasi silang dapat disimpulkan responden berjenis kelamin wanita merasa puas terhadap penilaian kinerja atribut kelengkapan, kesiapan 
96|Annas, Hubeis, Raharja - Kepuasan Nasabah dan Strategi Pengembangan Usaha

dan kebersihan alat-alat yang dipakai (atribut 17) dan ketersediaan fasilitas parkir yang memadai (atribut 20).

\section{III.6. Hubungan Usia dengan Kinerja Mutu Pelayanan BNI KCU Harmoni}

Berdasarkan hasil analisis karakteristik nasabah menurut umur memiliki hubungan kuat terhadap penilaian kinerja atribut petugas cepat tanggap dalam memberi pelayanan (atribut 3), kejujuran karyawan dalam bekerja (atribut 9), informasi mengenai produk yang ditawarkan lengkap dan jelas (brosur, iklan, pamflet, dan lain-lain) (atribut 12), kelengkapan, kesiapan dan kebersihan alat-alat yang dipakai (atribut 17), kemudahan mencapai lokasi (atribut 19) dan kesediaan fasilitas parkir yang me-madai (atribut 20). Dengan tingkat signifikansi kepercayaan 95\% diperoleh nilai proba-bilitas lebih kecil dari 0.05 dan nilai Khi-kuadrat hitung > nilai Khi-kuadrat tabel, maka terdapat hubungan kuat antara umur dengan penilaian kinerja atribut, sehingga $\mathrm{Ho}$ ditolak dan $\mathrm{H}_{1}$ diterima. Hal ini menunjukkan faktor usia nasabah berperan dalam penetapan atribut kinerja yang dimiliki oleh petugas BNI KCU Harmoni. Hasil uji Khi-kuadrat kinerja atribut yang berhubungan dengan usia dapat dilihat pada Tabel 3.

Tabel 3. Uji Khi-kuadrat kinerja atribut yang berhubungan dengan usia

\begin{tabular}{lcccccc}
\hline \multirow{2}{*}{ Khi-kuadrat } & \multicolumn{7}{c}{ ATRIBUT } \\
\cline { 2 - 7 } & $\mathbf{3}$ & $\mathbf{9}$ & $\mathbf{1 2}$ & $\mathbf{1 7}$ & $\mathbf{1 9}$ & $\mathbf{2 0}$ \\
\hline Khi-kuadrat Hitung & $16.890^{\mathrm{a}}$ & $17.752^{\mathrm{a}}$ & $17.161^{\mathrm{a}}$ & $19.450^{\mathrm{a}}$ & $18.219^{\mathrm{a}}$ & $\mathbf{2 5 . 2 8 4 ^ { \mathrm { a } }}$ \\
Khi-kuadrat Tabel & 16.507 & 16.507 & 16.507 & 16.507 & 16.507 & 16.507 \\
Peluang & 0.031 & 0.023 & 0.028 & 0.013 & 0.020 & 0.001 \\
Keputusan & Tolak Ho & Tolak Ho & Tolak Ho & Tolak Ho & Tolak Ho & Tolak Ho \\
\hline
\end{tabular}

III.7. Hubungan Pekerjaan dengan Kinerja Mutu Pelayanan BNI KCU Harmoni

Hasil analisis karakteristik nasabah menurut pekerjaan memiliki hubungan kuat terhadap kinerja atribut karyawan yang menerima pertanyaan dapat langsung dijawab dan mampu menyelesaikan keluhan/masalah (atribut 4), petugas memberikan informasi jelas dan mudah dimengerti (atribut 5), petugas keamanan (satpam) melayani dengan ramah dan sopan (atribut 7), petugas pelayanan memberikan pelayanan dan informasi dengan sikap yang ramah dan sopan (atribut 8), kejujuran karyawan dalam bekerja (atribut 9), keamanan sarana parkir kendaraan (atribut 11), informasi mengenai produk yang ditawarkan lengkap dan jelas (brosur, iklan, pamflet, dan lain-lain) (atribut 12), penyediaan bahan bacaan dan permen selama menunggu giliran (atribut 14), kelengkapan, kesiapan dan kebersihan alat-alat yang dipakai (atribut 17).

Dengan taraf kepercayaan 95\%, diperoleh nilai peluang lebih kecil dari 0.05 dan nilai Khi-kuadrat hitung > nilai Khi-kuadrat tabel, yang berarti terdapat hubungan kuat antara pekerjaan dengan penilaian kinerja atribut, maka Ho ditolak dan $\mathrm{H}_{1}$ diterima. $\mathrm{Hal}$ ini menunjukkan faktor pekerjaan nasabah berperan dalam penetapan atribut kinerja yang dimiliki oleh petugas BNI KCU Harmoni. Hasil uji Khi-kuadrat kinerja atribut yang berhubungan dengan pekerjaan dapat dilihat pada Tabel 4. 
Tabel 4. Uji Khi-kuadrat kinerja atribut yang berhubungan dengan pekerjaan

\begin{tabular}{|c|c|c|c|c|c|c|c|c|c|}
\hline \multirow{2}{*}{$\begin{array}{c}\text { Khi- } \\
\text { kuadrat }\end{array}$} & \multicolumn{9}{|c|}{ ATRIBUT } \\
\hline & 4 & 5 & 7 & 8 & 9 & 11 & 12 & 14 & 17 \\
\hline $\begin{array}{l}\text { Khi-kuadrat } \\
\text { Hitung }\end{array}$ & $86.783^{\mathrm{a}}$ & $69.049^{a}$ & $59.210^{\mathrm{a}}$ & $82.211^{a}$ & $86.100^{\mathrm{a}}$ & $85.549^{\mathrm{a}}$ & $85.233^{\mathrm{a}}$ & $75.074^{\mathrm{a}}$ & $81.648^{\circ}$ \\
\hline $\begin{array}{l}\text { Khi-kuadrat } \\
\text { Tabel }\end{array}$ & 28.296 & 28.296 & 28.296 & 28.296 & 28.296 & 28.296 & 28.296 & 28.296 & 28.296 \\
\hline Peluang & 0.000 & 0.000 & 0.000 & 0.000 & 0.000 & 0.000 & 0.000 & 0.000 & 0.000 \\
\hline & Tolak & Tolak & Tolak & Tolak & Tolak & Tolak & Tolak & Tolak & Tolak \\
\hline Keputusan & Ho & Ho & Ho & Ho & Ho & Ho & Ho & Ho & Ho \\
\hline
\end{tabular}

III.8. Hubungan Penghasilan dengan Kinerja Mutu Pelayanan BNI KCU Harmoni

Berdasarkan hasil analisis pada Tabel 5, pendapatan per bulan nasabah memiliki hubungan kuat terhadap penilaian kinerja atribut Pelayanan dilakukan dengan cepat dan tepat (atribut 2), Kejujuran karyawan dalam bekerja (atribut 9), Keamanan selama dalam pelayanan dan kepercayaan terhadap pelayanan yang diberikan (atribut 10), Keamanan sarana parkir kendaraan (atribut 11), Kerapihan dan kebersihan penampilan petugas (atribut 18). Dengan taraf kepercayaan 95\% diperoleh nilai probabilitas lebih kecil dari 0.05 dan nilai Khi-kuadrat hitung > nilai Khi-kuadrat tabel, yang berarti terdapat hubungan kuat pendapatan per bulan dengan penilaian kinerja atribut, maka Ho ditolak dan $\mathrm{H} 1$ diterima. Hal ini menunjukkan faktor pendapatan per bulan nasabah berperan dalam penetapan atribut kinerja yang dimiliki oleh petugas BNI KCU Harmoni. Hasil uji Khi-kuadrat kinerja atribut yang berhubungan dengan penghasilan dapat dilihat pada Tabel 5.

Tabel 5. Uji Khi-kuadrat kinerja atribut yang berhubungan dengan penghasilan

\begin{tabular}{lccccc}
\hline \multirow{2}{*}{ Khi-kuadrat } & $\mathbf{5}$ & $\mathbf{9}$ & $\mathbf{1 0}$ & $\mathbf{1 1}$ & $\mathbf{1 8}$ \\
\cline { 2 - 6 } & $86.718^{\mathrm{a}}$ & $86.100^{\mathrm{a}}$ & $86.383^{\mathrm{a}}$ & $85.549^{\mathrm{a}}$ & $91.149^{\mathrm{a}}$ \\
Khi-kuadrat Hitung & 28.296 & 28.296 & 28.296 & 28.296 & 28.296 \\
Khi-kuadrat Tabel & 0.000 & 0.000 & 0.000 & 0.000 & 0.000 \\
Peluang & Tolak Ho & Tolak Ho & Tolak Ho & TolakHo & Tolak Ho \\
Keputusan & & &
\end{tabular}

III.9. Hubungan Frekuensi Kunjungan dengan Kinerja Mutu Pelayanan BNI KCU Harmoni

Hasil analisis karakteristik nasabah menurut frekuensi kunjungan memiliki hubungan kuat terhadap kinerja atribut pelayanan dilakukan dengan cepat dan tepat (atribut 2), petugas memberikan informasi yang jelas dan mudah dimengerti (atribut $5)$, pengetahuan dan keterampilan petugas dalam memberikan pelayanan kepada nasabah (atribut 6), petugas keamanan (satpam) melayani dengan ramah dan sopan (atribut 7), keamanan selama dalam pelayanan dan kepercayaan terhadap pelayanan yang diberikan (atribut 10), kebersihan, kerapian dan kenyamanan ruang pelayanan (atribut 16), kelengkapan, kesiapan dan kebersihan alat-alat yang dipakai (atribut 17).

Dengan taraf nyata 95\% diperoleh nilai peluang lebih kecil dari 0.05 dan nilai Khikuadrat hitung > nilai Khi-kuadrat tabel, yang berarti terdapat hubungan kuat antara frekuensi kunjungan dengan penilaian kinerja atribut tersebut maka Ho ditolak dan $\mathrm{H}_{1}$ diterima. Hal ini menunjukkan faktor frekuensi kunjungan nasabah berperan dalam penetapan atribut kinerja yang dimiliki oleh petugas BNI KCU Harmoni. Hasil uji Khi- 
98|Annas, Hubeis, Raharja - Kepuasan Nasabah dan Strategi Pengembangan Usaha

kuadrat kinerja atribut yang berhubungan dengan frekuensi kunjungan dapat dilihat pada Tabel 6.

Tabel 6. Uji Khi-kuadrat kinerja atribut yang berhubungan dengan kinerja frekuensi kunjungan

\begin{tabular}{lccccccc}
\hline \multirow{2}{*}{ Khi-kuadrat } & \multicolumn{7}{c}{ ATRIBUT } \\
\cline { 2 - 8 } & $\mathbf{2}$ & $\mathbf{5}$ & $\mathbf{6}$ & $\mathbf{7}$ & $\mathbf{1 0}$ & $\mathbf{1 6}$ & $\mathbf{1 7}$ \\
\hline Khi-kuadrat Hitung & $56.560^{\mathrm{a}}$ & $59.258^{\mathrm{a}}$ & $68.708^{\mathrm{a}}$ & $42.274^{\mathrm{a}}$ & $63.681^{\mathrm{a}}$ & $38.940^{\mathrm{a}}$ & $59.363^{\mathrm{a}}$ \\
Khi-kuadrat Tabel & 28.296 & 28.296 & 28.296 & 28.296 & 28.296 & 28.296 & 28.296 \\
Peluang & 0.000 & 0.000 & 0.000 & 0.000 & 0.000 & 0.001 & 0.000 \\
Keputusan & Tolak Ho & Tolak Ho & Tolak Ho & Tolak Ho & Tolak Ho & Tolak Ho & Tolak Ho \\
\hline
\end{tabular}

III.10. Hubungan Sumber Informasi dengan Kinerja Mutu Pelayanan BNI KCU Harmoni

Hasil analisis karakteristik nasabah berdasarkan sumber informasi memiliki hubungan kuat terhadap kinerja atribut petugas cepat tanggap dalam memberi pelayanan (atribut 3). Dengan taraf nyata $95 \%$ diperoleh nilai probabilitas lebih kecil dari 0.05 dan nilai Khi-kuadrat hitung > nilai Khi-kuadrat tabel, yang berarti terdapat hubungan kuat sumber informasi dengan penilaian kinerja atribut tersebut maka Ho ditolak dan $\mathrm{H}_{1}$ diterima. Hal ini menunjukkan faktor sumber informasi nasabah berperan dalam penetapan atribut kinerja yang dimiliki oleh petugas BNI KCU Harmoni. Hasil uji Khi-kuadrat kinerja atribut yang berhubungan dengan sumber informasi dapat dilihat pada Tabel 7.

Tabel 7. Uji Khi-kuadrat kinerja atribut yang berhubungan dengan sumber informasi

\begin{tabular}{lc}
\hline \multicolumn{1}{c}{ Khi-kuadrat } & Atribut 3 \\
\hline Khi-kuadrat Hitung & $28.186^{\mathrm{a}}$ \\
Khi-kuadrat Tabel & 21.026 \\
Peluang & 0.005 \\
Keputusan & Tolak HO \\
\hline
\end{tabular}

III.11. Analisis Tingkat Kepentingan Nasabah dan Kinerja BNI KCU Harmoni terhadap Atribut-Atribut Mutu Pelayanan BNI KCU Harmoni

1. Analisis Kepentingan Nasabah

Berdasarkan data skor yang ditampilkan pada Tabel 8, dapat dihitung skor rataan kepentingan tiap-tiap atribut layanan $\left(\mathrm{Y}_{\mathrm{i}}\right)$ dengan cara membagi nilai skor kepentingan $\left(\mathrm{Y}_{\mathrm{i}}\right)$ dengan jumlah responden (100 orang). Pembagian tersebut menghasilkan angka rataan skor yang nilainya berkisar 1-5 sesuai skala Likert yang terdiri sangat penting (5), penting (4), cukup penting (3), kurang penting (2) dan tidak penting (1).

Angka rataan penilaian kepentingan $\left(\mathrm{Y}_{\mathrm{i}}\right)$ diurut dari skor terbesar ke skor terkecil. Dapat diketahui bahwa atribut-atribut layanan yang dianggap paling penting oleh responden adalah atribut no. 3 (skor 4.41), atribut no. 19 (skor 4.40), atribut no. 2 (skor 4.39), atribut no. 10 (skor 4.39), dan seterusnya. Terdapat atribut dengan skor rendah, yaitu atribut 13 , namun bukan berarti disimpulkan bahwa seluruh nasabah menganggap rendah tingkat kepentingan atribut tersebut, karena hanya terdapat 16 (enam belas) orang yang memberikan penilaian cukup baik. Dalam hal ini, atribut dengan skor kepentingan tinggi menunjukkan kontribusi terhadap kepuasan nasabah lebih nyata. Untuk itu, BNI KCU Harmoni harus memprioritaskan atribut-atribut 
tersebut, agar kinerjanya memuaskan. Dengan demikian, persepsi nasabah terhadap BNI KCU Harmoni sesuai atau paling dianggap memuaskan.

Tabel 8. Distribusi responden penilaian kepentingan atribut-atribut layanan

\begin{tabular}{|c|c|c|c|c|c|c|c|}
\hline & \multirow{2}{*}{ Atribut } & \multicolumn{5}{|c|}{ Skor } & \multirow{2}{*}{$\begin{array}{c}\text { Nilai } \\
\text { (Yi) }\end{array}$} \\
\hline & & 1 & 2 & 3 & 4 & 5 & \\
\hline \multicolumn{8}{|c|}{ Reliability } \\
\hline 1 & Produk yang ditawarkan lengkap. & 1 & 3 & 14 & 25 & 57 & $434^{*}$ \\
\hline 2 & Pelayanan dilakukan dengan cepat dan tepat. & - & 3 & 9 & 34 & 54 & 439 \\
\hline \multicolumn{8}{|c|}{ Responsiveness } \\
\hline 3 & Petugas cepat tanggap dalam memberi pelayanan. & - & 1 & 13 & 30 & 56 & 441 \\
\hline 4 & Karyawan yang menerima pertanyaan, serta keluhan dapat & & & & & & \\
\hline & $\begin{array}{l}\text { langsung dijawab dan mampu menyelesaikan } \\
\text { keluhan/masalah. }\end{array}$ & - & - & 17 & 30 & 53 & 436 \\
\hline 5 & $\begin{array}{l}\text { Petugas memberikan informasi jelas dan mudah } \\
\text { dimengerti. }\end{array}$ & - & - & 11 & 40 & 49 & 438 \\
\hline \multicolumn{8}{|c|}{ Assurance } \\
\hline 6 & $\begin{array}{l}\text { Pengetahuan dan keterampilan petugas dalam } \\
\text { memberikan pelayanan kepada nasabah. }\end{array}$ & - & - & 12 & 52 & 36 & $424^{*}$ \\
\hline 7 & $\begin{array}{l}\text { Petugas keamanan (satpam) melayani dengan ramah dan } \\
\text { sopan. }\end{array}$ & - & - & 13 & 40 & 47 & 434 \\
\hline 8 & $\begin{array}{l}\text { Petugas pelayanan memberikan pelayanan dan informasi } \\
\text { dengan sikap ramah dan sopan }\end{array}$ & - & - & 13 & 39 & 48 & 435 \\
\hline 9 & Kejujuran karyawan dalam bekerja & - & 1 & 10 & 45 & 44 & 432 \\
\hline 10 & $\begin{array}{l}\text { Keamanan selama dalam pelayanan dan kepercayaan } \\
\text { terhadap pelayanan yang di berikan. }\end{array}$ & - & - & 11 & 39 & 50 & 439 \\
\hline 11 & Keamanan sarana parkir kendaraan. & - & - & 9 & 46 & 45 & 436 \\
\hline \multicolumn{8}{|c|}{ Empahty } \\
\hline 12 & $\begin{array}{l}\text { Informasi mengenai produk yang ditawarkan lengkap dan } \\
\text { jelas (brosur, iklan, pamflet, dan lain-lain) }\end{array}$ & - & - & 10 & 49 & 41 & 431 \\
\hline 13 & $\begin{array}{l}\text { Petugas berusaha mengenal dan memberikan perhatian } \\
\text { secara individu kepada nasabah yang sering melakukan } \\
\text { transaksi. }\end{array}$ & - & - & 16 & 50 & 34 & 418 \\
\hline $\begin{array}{l}14 \\
\text { Tar }\end{array}$ & $\begin{array}{l}\text { Penyediaan bahan bacaan dan permen selama menunggu } \\
\text { giliran. } \\
\text { gibles }\end{array}$ & - & - & 10 & 50 & 40 & 430 \\
\hline 15 & Penataan interior dan layout ruangan yang baik. & - & - & 15 & 49 & 36 & 421 \\
\hline 16 & Kebersihan, kerapian dan kenyamanan ruang pelayanan. & - & 2 & 7 & 59 & 32 & 421 \\
\hline 17 & $\begin{array}{l}\text { Kelengkapan, kesiapan dan kebersihan alat-alat yang } \\
\text { dipakai }\end{array}$ & - & - & 10 & 51 & 39 & 429 \\
\hline 18 & Kerapihan dan kebersihan penampilan petugas & - & - & 11 & 56 & 33 & 422 \\
\hline 19 & Kemudahan mencapai lokasi & - & 1 & 8 & 41 & 50 & 440 \\
\hline 20 & Kesediaan fasilitas parkir memadai & & & 13 & 58 & 29 & 416 \\
\hline & TOTAL NILAI $\left(\Sigma X_{i}\right)$ & & & & & & 8616 \\
\hline
\end{tabular}

Keterangan :

Jumlah responden $(n)=100$ orang

Skala pernilaian : 1 = tidak baik; 2 = kurang baik; 3 = cukup baik; 4 = baik; 5 = sangat baik

Contoh : *434 $=(1 \times 1)+(2 \times 3)+(3 \times 14)+(4 \times 25)+(5 \times 57)$

\section{Analisis Kinerja Perusahaan}

Angka rataan penilaian kinerja $\left(X_{i}\right)$ disajikan pada Tabel 9. Dari tabel tersebut diketahui atribut mana yang dinilai nasabah paling baik diantara 20 artibut yang ada. Urutan atribut-atribut layanan yang kinerjanya dianggap paling baik oleh responden 
adalah atribut 15 (skor 4.65), atribut 13 (skor 4.50), atribut 16 (skor 4.40), atribut 20 (skor 4.19) dan seterusnya.

Bila dibandingkan dengan skala Likert dengan nilai tertinggi pada angka 5, skor tertinggi yang diraih BNI KCU Harmoni mencapai 4.65 (sangat baik). Di sisi lain, penilaian kinerja terburuk berada atribut 18 (skor 3.49) atau cukup baik. Secara keseluruhan, penilaian (X) responden terhadap kinerja BNI KCU Harmoni adalah baik, atau mendapat point 3.98 (dihitung dengan cara membagi total rataan masing-masing skor kinerja ( $\Sigma \mathrm{Xi})$ dengan nilai 20 yang merupakan jumlah atribut).

Tabel 9. Distribusi responden berdasarkan penilaian kinerja atribut-atribut layanan

\begin{tabular}{|c|c|c|c|c|c|c|c|}
\hline \multirow{2}{*}{\multicolumn{2}{|c|}{ Atribut }} & \multicolumn{5}{|c|}{ Skor } & \multirow{2}{*}{$\begin{array}{r}\text { Nilai } \\
(\mathrm{Xi})\end{array}$} \\
\hline & & 1 & 2 & 3 & 4 & 5 & \\
\hline \multicolumn{8}{|c|}{ Reliability } \\
\hline 1 & Menu pelayanan yang ditawarkan lengkap. & 3 & 2 & 8 & 59 & 28 & $407^{*}$ \\
\hline 2 & Pelayanan dilakukan dengan cepat dan tepat. & 4 & 4 & 17 & 36 & 39 & 402 \\
\hline \multicolumn{8}{|c|}{ Responsiveness } \\
\hline 3 & Petugas cepat tanggap dalam memberi pelayanan. & 4 & 4 & 16 & 45 & 31 & 395 \\
\hline 4 & $\begin{array}{l}\text { Karyawan yang menerima pertanyaan, serta keluhan dapat } \\
\text { langsung dijawab dan mampu menyelesaikan keluhan/ } \\
\text { masalah. }\end{array}$ & 1 & 9 & 29 & 28 & 33 & 383 \\
\hline 5 & $\begin{array}{l}\text { Petugas memberikan informasi yang jelas dan mudah } \\
\text { dimengerti. }\end{array}$ & 4 & 5 & 15 & 45 & 31 & 394 \\
\hline \multicolumn{8}{|c|}{ Assurance } \\
\hline 6 & $\begin{array}{l}\text { Pengetahuan dan keterampilan petugas dalam } \\
\text { memberikan pelayanan kepada nasabah. }\end{array}$ & 3 & 6 & 25 & 33 & 33 & 387 \\
\hline 7 & $\begin{array}{l}\text { Petugas keamanan (satpam) melayani dengan ramah dan } \\
\text { sopan. }\end{array}$ & 2 & 4 & 17 & 49 & 28 & 397 \\
\hline 8 & $\begin{array}{l}\text { Petugas pelayanan memberikan pelayanan dan informasi } \\
\text { dengan sikap ramah dan sopan }\end{array}$ & 7 & 13 & 24 & 23 & 33 & 362 \\
\hline 9 & Kejujuran karyawan dalam bekerja & 3 & 4 & 32 & 28 & 33 & 384 \\
\hline 10 & $\begin{array}{l}\text { Keamanan selama dalam pelayanan dan kepercayaan } \\
\text { terhadap pelayanan yang diberikan. }\end{array}$ & 1 & 1 & 25 & 32 & 41 & 411 \\
\hline 11 & Keamanan sarana parkir kendaraan. & 4 & 17 & 20 & 25 & 34 & 368 \\
\hline \multicolumn{8}{|c|}{ Empahty } \\
\hline 12 & $\begin{array}{l}\text { Informasi mengenai produk yang di tawarkan lengkap dan } \\
\text { jelas (brosur, iklan, pamflet, dan lain-lain) }\end{array}$ & 3 & 7 & 29 & 28 & 33 & 381 \\
\hline 13 & $\begin{array}{l}\text { Petugas berusaha mengenal dan memberikan perhatian } \\
\text { secara individu kepada nasabah yang sering melakukan } \\
\text { transaksi. }\end{array}$ & - & - & 3 & 44 & 53 & 450 \\
\hline 14 & $\begin{array}{l}\text { Penyediaan bahan bacaan dan permen selama menunggu } \\
\text { giliran. }\end{array}$ & - & 14 & 27 & 23 & 36 & 381 \\
\hline \multicolumn{8}{|c|}{ Tangibles } \\
\hline 15 & Penataan interior dan layout ruangan yang baik. & - & - & 1 & 33 & 66 & 465 \\
\hline 16 & Kebersihan, kerapian dan kenyamanan ruang pelayanan. & 1 & 3 & 3 & 41 & 52 & 440 \\
\hline 17 & $\begin{array}{l}\text { Kelengkapan, kesiapan dan kebersihan alat-alat yang } \\
\text { dipakai }\end{array}$ & 1 & 5 & 21 & 39 & 34 & 400 \\
\hline 18 & Kerapihan dan kebersihan penampilan petugas & 13 & 15 & 16 & 22 & 34 & 349 \\
\hline 19 & Kemudahan mencapai lokasi & 1 & 9 & 29 & 28 & 33 & 383 \\
\hline 20 & Kesediaan fasilitas parkir memadai & 4 & 1 & 13 & 36 & 46 & 419 \\
\hline & TOTAL NILAI $(\Sigma \mathrm{Xi})$ & & & & & & 7958 \\
\hline
\end{tabular}

Keterangan :

Jumlah responden $(n)=100$ orang

Skala pernilaian : 1 = tidak baik; 2 = kurang baik; 3 = cukup baik; 4 = baik; 5 = sangat baik Contoh : *407 $=(1 \times 3)+(2 \times 2)+(3 \times 8)+(4 \times 59)+(5 \times 28)$ 
III.12. Analisis Kesesuaian Tingkat Kepentingan Atribut-Atribut Mutu Pelayanan BNI KCU Harmoni dengan Kinerja BNI KCU Harmoni

Skor keseluruhan atribut kepentingan diperoleh berdasarkan distribusi penilaian kepentingan dari responden terhadap masing-masing atribut layanan dengan total nilai 7.990. Skor keseluruhan atribut kinerja/presepsi nasabah diperoleh berdasarkan distribusi penilaian persepsi/kinerja dari responden terhadap masing-masing atribut layanan dengan total nilai 7 876. Berdasarkan kedua nilai skor penilaian tersebut, tingkat kesesuaian secara keseluruhan adalah $92.36 \%$.

III.13. IPA

Dengan menggunakan diagram Kartesius, 20 atribut layanan dijabarkan dan dibagi menjadi empat (4) kuadran berdasarkan skor rataan masing-masing atribut layanan sesuai penilaian kepentingan dan kinerja (Xi dan Yi). Empat kuadran dari diagram Kartesius tersebut adalah Prioritas Utama (kiri atas), Pertahankan Presentasi (kanan atas), Prioritas Rendah (kiri bawah) dan berlebihan (kanan bawah). Terdapat dua belas (12) atribut yang masuk kuadran Prioritas Utama dan delapan (8) atribut Pertahankan Prestasi. Untuk ke depan diperlukan langkah perbaikan diantaranya melakukan survei kepuasaan nasabah secara berkala untuk mengetahui bagaimana posisinya di pasar dibandingkan dengan pesaing-pesaingnya. Hasil kajian menunjukan bahwa kinerja perusahaan yang perlu dipertahankan prestasinya, dimana terdapat delapan (8) atribut, yaitu : (1) Menu pelayanan yang ditawarkan lengkap, (2) Pelayanan dilakukan dengan cepat dan tepat, (3) Keamanan selama dalam pelayanan dan kepercayaan terhadap pelayanan yang di berikan, (4) Petugas berusaha mengenal dan memberikan perhatian secara individu kepada nasabah yang sering melakukan transaksi, (5) Penataan interior dan layout ruangan yang baik, (6) Kebersihan, kerapian dan kenyamanan ruang pelayanan, (7) Kelengkapan, kesiapan dan kebersihan alat-alat yang dipakai dan (8) Kesediaan fasilitas parkir yang memadai.

III.14. CSI

Tabel 10. Nilai CSI Tiap Atribut

\begin{tabular}{ccccccc}
\hline $\begin{array}{c}\text { Nomor } \\
\text { Atribut } \\
\text { Mutu jasa }\end{array}$ & $\begin{array}{c}\text { Rataan } \\
\text { Tingkat } \\
\text { Kepentingan }\end{array}$ & $\begin{array}{c}\text { Importance } \\
\text { Weighting } \\
\text { Factors (\%) }\end{array}$ & $\begin{array}{c}\text { Rataan } \\
\text { Tingkat } \\
\text { Kinerja }\end{array}$ & $\begin{array}{c}\text { Weighted } \\
\text { Score }\end{array}$ & $\begin{array}{c}\text { CSI Tiap } \\
\text { Atribut } \\
\text { (\%) }\end{array}$ & $\begin{array}{c}\text { Pembulatan } \\
\text { CSI } \\
\text { (\%) }\end{array}$ \\
\hline 1 & 4.34 & 5.04 & 4.07 & 0.21 & 4.10 & 4 \\
2 & 4.39 & 5.10 & 4.02 & 0.20 & 4.10 & 4 \\
3 & 4.41 & 5.12 & 3.95 & 0.20 & 4.04 & 4 \\
4 & 4.36 & 5.06 & 3.83 & 0.19 & 3.88 & 4 \\
5 & 4.38 & 5.08 & 3.94 & 0.20 & 4.01 & 4 \\
6 & 4.24 & 4.92 & 3.87 & 0.19 & 3.81 & 4 \\
7 & 4.34 & 5.04 & 3.97 & 0.20 & 4.00 & 4 \\
8 & 4.35 & 5.05 & 3.62 & 0.18 & 3.66 & 4 \\
9 & 4.32 & 5.01 & 3.84 & 0.19 & 3.85 & 4 \\
10 & 4.39 & 5.10 & 4.11 & 0.21 & 4.19 & 4 \\
11 & 4.36 & 5.06 & 3.68 & 0.19 & 3.72 & 4 \\
12 & 4.31 & 5.00 & 3.81 & 0.19 & 3.81 & 4 \\
13 & 4.18 & 4.85 & 4.50 & 0.22 & 4.37 & 4 \\
14 & 4.30 & 4.99 & 3.81 & 0.19 & 3.80 & 4 \\
\hline
\end{tabular}


102 |Annas, Hubeis, Raharja - Kepuasan Nasabah dan Strategi Pengembangan Usaha

Lanjutan Tabel 10.

\begin{tabular}{|c|c|c|c|c|c|c|}
\hline $\begin{array}{c}\text { Nomor } \\
\text { Atribut } \\
\text { Mutu jasa }\end{array}$ & $\begin{array}{c}\text { Rataan } \\
\text { Tingkat } \\
\text { Kepentingan }\end{array}$ & $\begin{array}{c}\text { Importance } \\
\text { Weighting } \\
\text { Factors (\%) }\end{array}$ & $\begin{array}{l}\text { Rataan } \\
\text { Tingkat } \\
\text { Kinerja }\end{array}$ & $\begin{array}{c}\text { Weighted } \\
\text { Score }\end{array}$ & $\begin{array}{c}\text { CSI Tiap } \\
\text { Atribut } \\
\text { (\%) }\end{array}$ & $\begin{array}{c}\text { Pembulatan } \\
\text { CSI } \\
\text { (\%) }\end{array}$ \\
\hline 15 & 4.21 & 4.89 & 4.65 & 0.23 & 4.54 & 4 \\
\hline 16 & 4.21 & 4.89 & 4.40 & 0.21 & 4.30 & 4 \\
\hline 17 & 4.29 & 4.98 & 4.00 & 0.20 & 3.98 & 4 \\
\hline 18 & 4.22 & 4.90 & 3.49 & 0.17 & 3.42 & 4 \\
\hline 19 & 4.40 & 5.11 & 3.83 & 0.20 & 3.91 & 4 \\
\hline 20 & 4.16 & 4.83 & 4.19 & 0.20 & 4.05 & 4 \\
\hline Total & 86.16 & 100.00 & 79.58 & & & \\
\hline $\begin{array}{l}\text { Weighted } \\
\text { Total }\end{array}$ & \multicolumn{4}{|c|}{3.98} & 79.53 & 80 \\
\hline Satisfaction & \multicolumn{4}{|c|}{79.53435469} & & \\
\hline
\end{tabular}

Berdasarkan hasil analisis CSI (Tabel 10) diketahui bahwa secara umum nasabah BNI KCU Harmoni berada pada kategori puas, maka BNI KCU Harmoni harus mampu menyusun suatu strategi untuk meningkatkan kepuasan nasabah. Tujuan dari strategi kepuasan nasabah adalah membuat agar nasabah tidak mudah pindah ke pesaing lain, karena mempertahankan nasabah yang sudah ada lebih sulit dibandingkan dengan mencari nasabah baru.

\section{III.15. Analisis SWOT}

Analisis total skor faktor strategik internal dan total skor faktor strategik eksternal dengan nilai total skor IFAS $=2.05$ dan EFAS $=2.60$ didapatkan matriks IE dari posisi BNI KCU Harmoni. Nilai matriks IE menunjukkan bahwa BNI KCU Harmoni berada pada kondisi growth

Tabel 11. Matriks SWOT BNI KCU Harmoni

\begin{tabular}{|c|c|c|}
\hline & Strength (S) & Weaknesses (W) \\
\hline Faktor Eksternal & $\begin{array}{l}\text { 1. S1 Kecepatan, keamanan dan ke- } \\
\text { percayaan selama dalam pela- } \\
\text { yanan kepada nasabah } \\
\text { 2. S2 Fasilitas fisik yang baik selama } \\
\text { dalam masa pelayanan }\end{array}$ & $\begin{array}{l}\text { 1. W1 Pelayanan parkir kendaraan } \\
\text { yang aman dan nyaman } \\
\text { 2. W2 Promosi/Iklan }\end{array}$ \\
\hline $\begin{array}{l}\text { Opportunities (0) } \\
\text { 1. O1 Pangsa Pasar } \\
\text { Luas/Daerah Padat } \\
\text { 2. O2 Kebutuhan } \\
\text { masyarakat akan } \\
\text { transaksi perbankan }\end{array}$ & $\begin{array}{l}\text { Strategi S- } \mathbf{~} \\
\text { 1. Mempertahankan mutu dan ke- } \\
\text { ahlian dengan standar pelayan- } \\
\text { an prima untuk masyarakat luas } \\
\text { sesuai kebutuhan (S1, S2; O1, } \\
\text { O2) } \\
\text { 2. Merawat dan fasilitas yang baik } \\
\text { sesuai dengan kebutuhan masya- } \\
\text { rakat untuk melakukan transaksi } \\
\text { perbankan. }(\mathrm{S} 2, \mathrm{O} 2)\end{array}$ & $\begin{array}{l}\text { Strategi } \mathbf{W}-\mathbf{O} \\
\text { 1. Melakukan koordinasi dengan } \\
\text { pengelola gedung untuk me- } \\
\text { nyediakan ruang parkir khusus } \\
\text { untuk nasabah BNI (W1; O1, O2) } \\
\text { 2. Melakukan promosi atau pe- } \\
\text { masangan iklan yang ditujukan } \\
\text { untuk pangsa pasar yang luas } \\
\text { dan sesuai kebutuhan masya- } \\
\text { rakat (W2 dan O2) }\end{array}$ \\
\hline
\end{tabular}


Lanjutan Tabel 11

\begin{tabular}{|c|c|c|}
\hline Threats (T) & Strategi S - T & Strategi $\mathbf{W}-\mathbf{T}$ \\
\hline $\begin{array}{l}\text { 1. T1 Banyaknya bank } \\
\text { pesaing di sekitar } \\
\text { BNI KCU Harmoni }\end{array}$ & $\begin{array}{l}\text { 1. Mutu pelayanan dan keahlian yang } \\
\text { dimiliki oleh petugas BNI KCU Har- } \\
\text { moni dapat menjadi positioning }\end{array}$ & $\begin{array}{l}\text { 1. Melakukan benchmarking ke } \\
\text { bank-bank pesaing di sekitar BNI } \\
\text { KCU Harmoni (W1, W2; T1, T2) }\end{array}$ \\
\hline $\begin{array}{l}\text { 2. T2 Daya beli } \\
\text { Masyarakat }\end{array}$ & $\begin{array}{l}\text { BNI KCU Harmoni diantara bank- } \\
\text { bank lainnya dalam menarik minat } \\
\text { masyarakat (S1, S2, S3; T1, T2) } \\
\text { 2. Melakukan diversifikasi pelayanan } \\
\text { BNI KCU Harmoni sesuai dengan } \\
\text { minat masyarakat. (S1, T1,T2) }\end{array}$ & $\begin{array}{l}\text { 2. Membuat promosi iklan yang } \\
\text { lebih menarik dari bank pesaing } \\
\text { dan melakukan penyesuaian tarif } \\
\text { dengan daya beli masyarakat. } \\
(\mathrm{W} 2 ; \mathrm{T} 1, \mathrm{~T} 2)\end{array}$ \\
\hline
\end{tabular}

Keterangan : ( $\mathrm{Si}$; Oi) atau ( $\mathrm{Wi}$; Oi) atau (Si ; Ti) atau (Wi ; Ti) menunjukkan kombinasi lingkungan eksternal dengan internal dalam menghasilkan pilihan strategi

$i=1,2, \ldots \ldots \ldots . . . N$

\section{III.16. Implementasi Strategi}

Secara keseluruhan dari hasil integrasi IPA, CSI dan SWOT menunjukkan bahwa nasabah telah merasa puas dengan pelayanan yang telah diberikan BNI KCU Harmoni. Kepuasan ini harus dibandingkan (benchmarking) dengan pelayanan yang diberikan oleh bank-bank pesaing di sekitar BNI KCU Harmoni agar pelayanan dapat lebih ditingkatkan menjadi lebih baik. Hasil kajian ini dapat dilakukan replikasi ke unit lainnya, agar dapat meningkatkan mutu pelayanan sesuai klasifikasi bisnis yang telah ditetapkan. Hal ini didasarkan pada sifat dari penelitian yang universal, sehingga dapat diterapkan pada industri jasa-jasa yang lain. Penelitian selanjutnya diharapkan dapat dilakukan dengan melakukan studi perbandingan antara pelayanan yang diberikan oleh BNI KCU Harmoni dibandingkan dengan bank-bank pesaing di sekitar BNI KCU Harmoni.

\section{Kesimpulan}

Karakteristik contoh nasabah BNI KCU Harmoni sebagian besar adalah wanita berusia 36-55 tahun, bekerja sebagai karyawati dengan penghasilan di atas Rp 8 juta per bulan dan merupakan konsumen baru yang mendapatkan informasi dari spanduk yang dipasang di depan BNI KCU Harmoni.

Berdasarkan hubungan karakteristik jenis kelamin dan tingkat kinerja dapat dilihat bahwa nasabah wanita merasa puas terhadap penilaian kinerja atribut kelengkapan, kesiapan dan kebersihan alat-alat yang dipakai, ingin merasa nyaman dan aman selama melakukan dilayani dan juga merasa puas dengan ketersediaan fasilitas parkir memadai. Nasabah berumur 36-55 tahun menilai sangat baik untuk penilaian kinerja informasi mengenai produk yang ditawarkan lengkap dan jelas (brosur, iklan, pamflet, dan lain-lain). Hal lainnya ditemukan bahwa karyawan dan pengusaha memiliki hubungan kuat terhadap kinerja atribut petugas, yang bersumber dari latar belakang pendidikan nasabah; penghasilan di atas Rp 8 juta per bulan memiliki hubungan kuat terhadap penilaian kinerja atribut keamanan selama dalam pelayanan dan kepercayaan terhadap pelayanan yang diberikan, frekuensi kunjungan, kinerja atribut pengetahuan dan keterampilan petugas dalam memberikan pelayanan kepada nasabah yang nantinya dapat membuat nasabah kembali melakukan transaksi di BNI KCU Harmoni; sumber informasi memiliki hubungan kuat terhadap kinerja 
atribut petugas cepat tanggap dalam memberikan pelayanan informasi, sehingga petugas memberikan pelayanan lebih cepat tanpa harus menjelaskan secara rinci.

Menurut tingkat kepentingan nasabah, atribut-atribut layanan yang dianggap paling penting oleh nasabah adalah atribut petugas cepat tanggap dalam memberikan pelayanan, kemudahan mencapai lokasi dan pelayanan dilakukan dengan cepat dan tepat. Dilihat tingkat kesesuaian masing-masing 20 atribut layanan, terdapat dua belas (12) atribut yang harus mendapat prioritas utama untuk diperbaiki dan dilaksanakan sesuai dengan harapan nasabah, mengingat bobot kepentingannya yang nyata dalam memengaruhi kepuasan nasabah. Berdasarkan hasil analisis CSI, diketahui bahwa secara umum nasabah BNI KCU Harmoni berada pada kategori cukup puas, maka harus mampu disusun suatu strategi untuk meningkatkan kepuasan nasabah.

Dari matriks faktor strategi dihasilkan total skor faktor strategik internal dan eksternal melalui matriks Internal Eksternal (IE) yang menentukan posisi BNI KCU Harmoni berada pada kondisi growth, sehingga harus dilakukan strategi informasi mengenai produk yang ditawarkan lengkap dan jelas secara lebih agresif, serta tepat sasaran di lingkungan sekitar (brosur, iklan, pamflet, dan lain-lain) dengan melakukan revisi terhadap bahasa promosi, desain dan layout agar dapat menarik nasabah.

\section{Daftar Pustaka}

Arikunto S. 2006. Prosedur Penelitian: Suatu Pendekatan Praktek. Jakarta (ID): PT. Rineka Cipta.

Berry LL, Parasuraman A. 1991. Marketing Services Competing Through Quality. Singapore (SG) : The Free Press Maxwll Macmillan Int'l.

Freund EF and FJ Williams. 1974. Modern Business Statistics. New Jersey (US): Prentice-Hall, Inc, Englewoods Cliffs

Hubeis M. 1997. Menuju Industri Profesional di Era Globalisasi melalui Pemberdayaan Manajemen Industri. Makalah Orasi Ilmiah Guru Besar. Fakultas Teknologi Pertanian. Bogor (ID): Institut Pertanian Bogor.

Marimin. 2005. Teknik dan Aplikasi Pengambilan Keputusan Kriteria Majemuk. Jakarta (ID): PT Gramedia Widiasarana Indonesia.

Rangkuti F. 2006. Measuring Customer Satisfaction. Jakarta (ID): PT Gramedia Pustaka Utama.

Subihaini. 2002. Analisis Konsekuensi Keperilakuan Kualitas Layanan: Suatu Penelitian Empiris. Usahawan. 31 (2): 29-37.

Sugiyono. 2002. Metode Penelitian Bisnis. Bandung (ID): CV Alfabeta.

Supardi. 2005. Metode Penelitian Ekonomi dan Bisnis. Yogyakarta (ID): UII Press.

Supranto J. 2001. Pengukuran Tingkat Kepuasaan Pelanggan. Jakarta (ID): Penerbit Rineka Cipta. 